\title{
Treatment Outcome and Associated Factors of Neonatal Sepsis at Mizan Tepi University Teaching Hospital, South West Ethiopia: A Prospective Observational Study
}

\author{
Alemnew Wale $\mathbb{D D}^{\prime}$ \\ Legese Chelkeba $\mathbb{D D}^{2}$ \\ Yohannes Wobie ${ }^{3}$ \\ Abinet Abebe $\mathbb{D D}^{3}$ \\ 'Clinical Midwifery, Department of \\ Midwifery, College of Medicine and \\ Health Science, MizanTepi University, \\ Mizan, Ethiopia; ${ }^{2}$ Clinical Pharmacy, \\ School of Pharmacy, Institute of Health, \\ Addis Ababa University, Addis Ababa, \\ Ethiopia; ${ }^{3}$ Clinical Pharmacy, School of \\ Pharmacy, College of Medicine and \\ Health Science, MizanTepi University, \\ Mizan, Ethiopia
}

\begin{abstract}
Introduction: Neonatal sepsis is the gravest problem in neonates, ending in significant morbidity and mortality. World wide 6.9 million neonates were spotted with potentially severe bacterial infections needing treatment and 2.6 million of them occurred in subSaharan Africa (SSA). Sepsis is the leading cause of neonatal mortality and is perhaps answerable for about $30-50 \%$ of the total neonatal deaths per year in emerging countries.

Objective: This study aims to assess the treatment outcome and associated factors of neonatal sepsis at Mizan Tepi University Teaching Hospital, South West Ethiopia.

Methods: A hospital-based prospective observational study was done at Mizan Tepi University Teaching Hospital (MTUTH) from May to November 2019 among neonates admitted with sepsis. Data were entered to Epi-data 4.2 and analyzed by SPSS version 21 . Bivariate and multivariate Cox regression was used to identify the relationship between dependent and independent variables. All neonates $\leq 28$ days who were admitted to MTUTH at the neonatal intensive care unit (NICU) and neonates diagnosed with sepsis by the attending physician either clinically or laboratory-confirmed included in the study.

Results: Of the 211 neonatal sepsis patients, 110 (52.1\%) were females, 161 (76.3\%) were admitted with late-onset sepsis, 16 (7.6\%) were very low birth weight, and $156(73.9 \%)$ were term. About $143(67.8 \%)$ had a good outcome and $68(32.2 \%)$ had a poor outcome. Very low birth weight $[\mathrm{P}=0.006, \mathrm{AHR}=1.692,95 \% \mathrm{CI}:(1.245,4.36)]$, age of neonate being less than 4 days at admission $[\mathrm{P}=0.001, \mathrm{AHR}=9.67,95 \% \mathrm{CI}:(2.24,41.70)]$, maternal infection $[\mathrm{P}=$ $0.032, \mathrm{AHR}=3.186,95 \% \mathrm{CI}:(1.32,30.68)]$, and prolonged length of hospital stay $[(\mathrm{P}=$ $0.017, \mathrm{AHR}=12.29,95 \% \mathrm{CI}:(1.55,96.31)$, were significantly associated to mortality.
\end{abstract}

Conclusion: The mortality rate of neonatal sepsis was found to be high. Age of neonate $<4$ days, birth weight of the neonate $<1500 \mathrm{gm}$, and prolonged length of hospital stay were identified as independently associated factors of increased risk of mortality.

Keywords: neonate, sepsis, treatment outcome, Mizan, Ethiopia 2021

\section{Introduction}

According to the international pediatrics agreement symposium, neonatal sepsis (NS) is well-defined as systemic inflammatory response syndrome in the presence of or as a result of suspected or proven infection in a neonate. Neonatal sepsis is the gravest problem in neonates, ending in significant morbidity and mortality. ${ }^{1}$ Neonatal sepsis is divided into early-onset and late-onset sepsis, based on the timing of infection and presumed mode of transmission. Early-onset sepsis
Correspondence: Alemnew Wale Yohannes Wobie

Email walealemnew@gmail.com; yohanneswobie@gmail.com 
(EONS) within the first 72 hours is caused by the maternal intrapartum transmission of invasive organisms. Lateonset sepsis (LONS) occurs after 72 hours of birth and is attributed to pathogens acquired postnatal. ${ }^{2}$

World wide 130 million infants are born per year and 14 million neonates die in the first 28 days of life. ${ }^{3}$ Threefourths of neonatals died in the first week, and more than one-fourth occur in the first 24 hours. Globally more than $40 \%$ of neonatals die under the age of 5 years and twothirds of the world's neonatal deaths occur mostly in Asia and Africa. ${ }^{4}$ The occurrence of NS fluctuates from 6 to 9 cases per 1000 live births but is higher among low-birthweight neonates. Bacterial sepsis is the main cause of neonatal mortality. ${ }^{5}$

Early-onset sepsis (EONS) usually is caused by organisms acquired from the mother's genitals. The most common organisms in EONS are Group B Streptococcus $(50 \%)$ and Escherichia coli $(20 \%)$. Whereas for LONS around $70 \%$ are due to gram-positive infections, such as CoNS, Staphylococcus aureus, and Enterococcus. ${ }^{6}$

The most common clinical manifestations of neonatal sepsis are altered behavior, muscle tone, feed refusal, feed intolerance, including vomiting, excessive gastric aspirates and abdominal distension, temperature instability, hypotension, poor perfusion with pallor and mottled skin, metabolic acidosis, tachycardia or Brady cardiac, apnea, respiratory distress, grunting, cyanosis, irritability, lethargy, seizures, petechial, purpura, and bleeding. Therefore neonatal sepsis can be diagnosed if at least two of the above clinical manifestations feature and at least two of the following laboratory values are positive, such as, complete blood count (CBC) with differential, blood culture, urine culture, chest radiograph (if respiratory signs present), gram stain, lumbar puncture (CSF) examination especially for late-onset sepsis and late late sepsis. $^{7-9}$

The variety of microorganisms that cause neonatal sepsis changes over time; this is because of the changing pattern of antibiotic use and lifestyle changes. The mortality of neonatal sepsis is reduced by early diagnosis and proper management of neonatal sepsis. ${ }^{10}$ Even if blood culture is the gold standard for the diagnosis of sepsis, it is only available after 48 to 72 hours. There is a need to recognize the common bacteria causing infections in every hospital and their susceptibility patterns to provide the necessary information for a timely intervention. ${ }^{11}$ Therefore this study aims to assess the treatment outcome and associated factors of neonatal sepsis at Mizan Tepi University Teaching Hospital, South West Ethiopia.

\section{Method}

\section{Study Area and Period}

The study was done in Mizan Tepi University Teaching Hospital (MTUTH) situated in Mizan Aman town, Bench Sheko zone which is one of the zones in the South Nation Nationalities and People Region (SNNPR) and situated about $561 \mathrm{~km}$ from Addis Ababa. The study was done from 1 May 2019 to 30 November 2019. The category of health personnel in the neonatal intensive care unit (NICU) was 3-degree nurses, 4 midwives, 5 general practitioners, and 2 pediatricians.

A hospital-based prospective observational study design was used and all neonates were admitted to the MTUTH's NICU. Neonates fulfilling the inclusion criteria who were admitted to MTUTH's NICU with the diagnosis of neonatal sepsis during the study period was the study population. The sample size was calculated by using the single population proportion formula taking the proportion of mortality $13.1 \%{ }^{12}$ and by considering $95 \%$ confidence interval (CI) and 5\% marginal error, the final sample size was 192.5 193.

All neonates $\leq 28$ days who were admitted to MTUTH at the NICU and neonates diagnosed with sepsis by the attending physician either clinically or laboratory-confirmed are included in the study and those neonates having an incomplete patient chart as well as neonatal mothers unable to speak and hear in the absence of a translator were excluded. Permission for data collection was obtained from the hospital administrator's office. Data were collected by using a semi-structured questionnaire and chart review. The questionnaire was adapted from a review of related previous literature. ${ }^{13,14}$ Data were collected by four data collectors with experience in data collection. The data collection tool included socio-demographic variables (mother's and neonatal age, maternal educations, residence, and occupational status), clinical variables (convulsion, severe chest in drowning, lethargic or unconscious, reduced movement, and not able to feed), laboratory variables (CBC, culture, gram stain CSF and ESR) and outcome variables (poor and good). In addition, vital signs (like PR, RR, and temperature and oxygen saturation) were collected. The outcome was evaluated based on clinical features, vital signs, laboratory investigations, and patient summary notes during discharge from the hospital. 
Data were cleaned, coded, and entered into Epi-data version 4.2 software, and then exported to SPSS version 21 for analysis. Cox regression was used to analyze factors associated with mortality. Bivariate Cox regression was done to see associations between mortality and independent variables. Then, variables having a $\mathrm{P}$-value $<0.25$ were eligible for multivariate Cox regression analysis to evaluate time to the event and independently associated factors of mortality due to neonatal sepsis. Those variables having P-value $<0.05$ were considered statistically significant.

\section{Ethical Clearance}

Ethical approval was gathered from Jimma University Ethical Review Committee and permission to conduct the study was obtained from Mizan Tepi University Teaching Hospital, Department of Pediatrics. The verbal informed consent was also approved by the ethical committee and obtained from the patient's parent or care-giver. Neonatal parents were given information regarding the objectives of the study and they had the right either to decline or participate in this study. The participants' privacy was confidential and anonymous. This study was conducted under the Declaration of Helsinki.

\section{Outcome Measurement and Validating Methods}

Treatment outcomes (good and poor) were measured using parameters such as whether the presence or absence of clinical signs and symptoms, vital sign instability and laboratory abnormality, and patient summary note while taking and after completion of the treatment course. The patients were followed starting from admission to discharge or from time to event.

Prevalence was also determined by calculating the number of all neonatal sepsis cases admitted within this study period (1 May 2019 to 30 November 2019) that fulfilled the admission criteria divided by the size of all neonates admitted to the NICU during this period. Thus,

$$
\text { Prevalence }=\frac{\text { Number of neonatal sepsis disease onsets }}{\text { Sum of all neonates admitted }}
$$

\section{Operational and Term Definitions}

Neonatal Sepsis: sepsis diagnosed either clinically or with laboratory-confirmation by professionals or attending physicians during admission of the neonates. ${ }^{2}$

Neonate: newborn from birth to 28 days old. ${ }^{15}$
Prevalence: proportion of neonatal sepsis to the whole admission of neonates during the study period.

Early-onset: if sepsis occurs from birth to 3 days of age. ${ }^{15}$

Late-onset: if sepsis occurs between 4 and 28 days of age. ${ }^{15}$

Treatment outcome: clinical conditions of patients written on patients chart at discharge time.

Poor outcome: the attainment of one of the following results, death, self-discharge against medical advice with no improvement, complication, referred, deteriorated.

Primary outcome: mortality

Secondary outcome: complication, self-discharge, deteriorated, referred.

Good outcome: the attainment of improvement.

Died: a patient declared as expired in hospital by attending physician.

Improved: a patient who is free from signs and symptoms of neonatal sepsis and also having stabilized vital signs.

Deteriorated: patient discharged with a more severe sign and symptom than on diagnosis.

Self-discharged: patients discharged themselves without physicians' decision against medical care.

Referred: patients referred to other health institutions for better management of the condition.

Comorbidity: coexistence of one or more diseases with neonatal sepsis.

Length of hospital stay: the period from admission to an event such as; death, improvement, complication, referred, deteriorated, and self-discharge.

\section{Result \\ Socio-Demographic Characteristics of the Respondents in Southwest Ethiopia}

Out of 219 neonates admitted with sepsis, 8 were excluded from the study due to incomplete patient charts at admission. Two hundred eleven (211) were eligible for the study with a response rate of $96.4 \%$.

In this finding, the mean age of neonates was 13.4 \pm 7.75 (SD) days and they were in the age group of birth to 28 days. The mean age of mothers was $30.3 \pm 5.0$ (SD) years with the age group of 19-44 years. More than half of neonates $(52.1 \%)$ were female. In total, 106 (50.2\%) mothers were between ages 18 and 29 years old, about $117(55.5 \%)$ mothers were rural residents. The majority of $181(85.8 \%)$ of mothers were married, while $13(6.2 \%), 9$ $(4.3 \%)$, and $8(3.8 \%)$ mothers were single, widowed, and divorced, respectively. Of the total, 135 (64\%) mothers were housewives, and 59 (28\%) were illiterate (Table 1). 
Table I Socio-Demographic Characteristics of the Neonate with Their Mothers Admitted to Mizan Tepi University Teaching Hospital, South West Ethiopia in 2021 ( $n=211)$

\begin{tabular}{|c|c|c|c|}
\hline Variables & Category & Frequency & Percent \\
\hline $\begin{array}{l}\text { Age of } \\
\text { mothers }\end{array}$ & $\begin{array}{l}18-29 \\
30-34 \\
>34\end{array}$ & $\begin{array}{l}106 \\
57 \\
48\end{array}$ & $\begin{array}{l}50.2 \\
27 \\
22.7\end{array}$ \\
\hline Residence & $\begin{array}{l}\text { Urban } \\
\text { Rural }\end{array}$ & $\begin{array}{l}94 \\
117\end{array}$ & $\begin{array}{l}44.5 \\
55.5\end{array}$ \\
\hline $\begin{array}{l}\text { Maternal } \\
\text { status }\end{array}$ & $\begin{array}{l}\text { Married } \\
\text { Single } \\
\text { Window } \\
\text { Divorced }\end{array}$ & $\begin{array}{l}181 \\
13 \\
9 \\
8\end{array}$ & $\begin{array}{l}85.8 \\
6.2 \\
4.3 \\
3.8\end{array}$ \\
\hline $\begin{array}{l}\text { Occupation } \\
\text { of mother }\end{array}$ & $\begin{array}{l}\text { Housewife } \\
\text { Government organization } \\
\text { Businesswoman } \\
\text { Farmer } \\
\text { Student }\end{array}$ & $\begin{array}{l}135 \\
12 \\
41 \\
9 \\
14\end{array}$ & $\begin{array}{l}64 \\
5.7 \\
19.4 \\
4.3 \\
6.6\end{array}$ \\
\hline $\begin{array}{l}\text { Maternal } \\
\text { education }\end{array}$ & $\begin{array}{l}\text { Cannot read and write } \\
\text { but any formal education } \\
\text { Can read and write } \\
\text { Primary } \\
\text { Secondary } \\
\text { College and above }\end{array}$ & $\begin{array}{l}59 \\
75 \\
31 \\
36 \\
10\end{array}$ & $\begin{array}{l}28 \\
35.5 \\
14.7 \\
17.1 \\
4.7\end{array}$ \\
\hline $\begin{array}{l}\text { Sex of } \\
\text { neonates }\end{array}$ & $\begin{array}{l}M \\
F\end{array}$ & $\begin{array}{l}101 \\
110\end{array}$ & $\begin{array}{l}47.9 \\
52.1\end{array}$ \\
\hline $\begin{array}{l}\text { Age of } \\
\text { neonates }\end{array}$ & $\begin{array}{l}\text { Birth-3 days } \\
4-28 \text { days }\end{array}$ & $\begin{array}{l}50 \\
161\end{array}$ & $\begin{array}{l}23.7 \\
76.3\end{array}$ \\
\hline
\end{tabular}

\section{Prevalence of Neonatal Sepsis}

From 1 May 2019 to 30 November 2019 there were 838 neonates admitted at Mizan Tepi University Teaching Hospital in the NICU. Of the total neonates, 453 (54.1\%) were females. Out of the total neonates 219 were diagnosed with neonatal sepsis which gives a prevalence of $26.1 \%$ neonatal sepsis.

Number of neonatal sepsis

$$
\begin{aligned}
& \text { Prevalence of } \\
& \text { neonatal sepsis }
\end{aligned}=\frac{\text { cases in six month }}{\begin{array}{l}
\text { s of all neonate admitted } \\
\text { in six month }
\end{array}}
$$

Prevalence of neonatal sepsis $=\frac{219}{838} \times 100=26.1 \%$

\section{Neonatal Characteristics}

Of the total, 161 (76.3\%) were admitted with late-onset sepsis or age greater than 3 days. From the total $16(7.6 \%)$ were very low birth weight, $124(65.9 \%)$ were low birth weight, 156 (73.9\%) were term (37-42 weeks), 72 (34.1\%) were presented with comorbidities, 114 (54\%) neonates had a history of birth resuscitation, and 134 (62.6\%) neonates had an APGAR score less than seven. Most, 165 (78.2\%) neonates, were treated with ampicillin plus gentamycin (Table 2).

Of all admitted neonatal sepsis patients, 161 (76.3) were late-onset neonatal sepsis (LONS), and 50 (23.7\%) were early-onset neonatal sepsis (EONS) (Figure 1).

\section{Maternal Related Factors}

More than half of the women 124 (58.8\%) were primigravida. The majority $136(64.5 \%)$ of the women had no ANC visit and 60 (28.2\%) women had a history of infection during their pregnancy, of these $35(16.6 \%)$ women had a history of urinary tract infections. Ten (5.2\%) mothers were twin delivered with either one having neonatal sepsis. One hundred and seventy-four (82.5\%) women delivered their newborn in a health institution and $37(17.5 \%)$ women delivered by operation, 65 $(30.8 \%)$ of the women had a history of premature rupture of membrane (PROM). (Table 3).

Table 2 Neonatal Related Characteristics for Treatment Outcome of Neonatal Sepsis Patients Admitted to Mizan Tepi University

\begin{tabular}{|c|c|c|c|}
\hline Variables & Category & Frequency & Percent \\
\hline Birth weight & $\begin{array}{l}\text { Very low birth } \\
\text { weight }(1000- \\
\text { I500gm }) \\
\text { Low birth weight } \\
(150 \mid-2500 \mathrm{gm}) \\
\text { Normal birth weight } \\
(250 \mid-4000 \mathrm{gm})\end{array}$ & $\begin{array}{l}16 \\
124 \\
34\end{array}$ & $\begin{array}{l}7.6 \\
65.9 \\
20.9\end{array}$ \\
\hline Age of neonates & $\begin{array}{l}\text { Birth-3 days } \\
4-28 \text { days }\end{array}$ & $\begin{array}{l}50 \\
161\end{array}$ & $\begin{array}{l}23.7 \\
76.3\end{array}$ \\
\hline $\begin{array}{l}\text { Gestational age at } \\
\text { birth (weeks) }\end{array}$ & $\begin{array}{l}\text { Preterm(<37 weeks) } \\
\text { Full-term( } 37-42 \\
\text { weeks })\end{array}$ & $\begin{array}{l}55 \\
156\end{array}$ & $\begin{array}{l}26.1 \\
73.9\end{array}$ \\
\hline Had resuscitation & $\begin{array}{l}\text { Yes } \\
\text { No }\end{array}$ & $\begin{array}{l}114 \\
97\end{array}$ & $\begin{array}{l}54 \\
46\end{array}$ \\
\hline $\begin{array}{l}\text { APGAR score at } \\
5 \text { minute }\end{array}$ & $\begin{array}{l}<3 \\
4-6 \\
>7\end{array}$ & $\begin{array}{l}1 \\
13 \mid \\
63\end{array}$ & $\begin{array}{l}0.5 \\
62.1 \\
33.6\end{array}$ \\
\hline $\begin{array}{l}\text { Had } \\
\text { comorbidities }\end{array}$ & $\begin{array}{l}\text { Yes } \\
\text { No }\end{array}$ & $\begin{array}{l}72 \\
139\end{array}$ & $\begin{array}{l}34.1 \\
66.9\end{array}$ \\
\hline
\end{tabular}
Teaching Hospital, South West Ethiopia 202I ( $n=21$ I) 


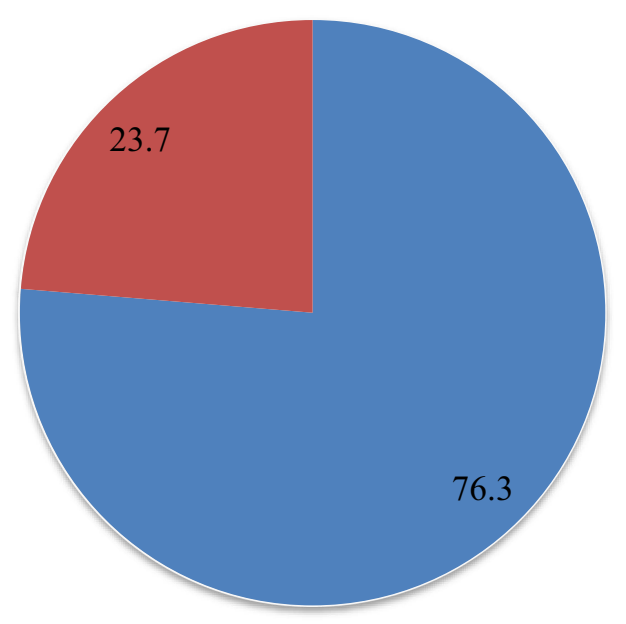

Figure I Types of sepsis among neonatal sepsis patients admitted to Mizan Tepi University Teaching Hospital, South West Ethiopia $2021(n=211)$.

\section{Clinical Parameters}

\section{Sign and Symptom}

During admission, almost all patients fulfill WHO clinical diagnosing criteria except for $60(28.4 \%)$ patients who manifested hypotension (Table 4).

\section{Laboratory Findings}

Of all neonatal sepsis patients, 203 (96.2\%) were diagnosed by CBC, 25 (11.8\%) were diagnosed with culture, $41(19.4 \%)$ with gram stain, and $58(27.5 \%)$ with a CSF

Table 3 Maternal Related Factors for Treatment Outcome of Neonatal Sepsis Patients Admitted to Mizan Tepi University Teaching Hospital, South West Ethiopia 202I ( $n=21$ I)

\begin{tabular}{|c|c|c|c|}
\hline Variables & Category & Frequency & Percent \\
\hline \multirow[t]{2}{*}{ Multiple births } & Yes & 87 & 41.2 \\
\hline & No & 124 & 58.8 \\
\hline \multirow[t]{3}{*}{ Place of delivery } & Home & 37 & 17.5 \\
\hline & Health & 174 & 82.5 \\
\hline & institution & & \\
\hline \multirow[t]{4}{*}{ Mode of delivery } & Vaginal & 174 & 82.5 \\
\hline & delivery & & \\
\hline & Cesarean & 37 & 17.5 \\
\hline & section & & \\
\hline \multirow{2}{*}{$\begin{array}{l}\text { Maternal infection during } \\
\text { pregnancy }\end{array}$} & Yes & 60 & 28.4 \\
\hline & No & $|5|$ & 71.6 \\
\hline \multirow[t]{2}{*}{ History of PROM } & Yes & 65 & 30.8 \\
\hline & No & 146 & 69.2 \\
\hline \multirow[t]{2}{*}{ ANC follow up } & Yes & 75 & 35.5 \\
\hline & No & 136 & 64.5 \\
\hline
\end{tabular}

Table 4 Clinical Presentation and Vital Sign of Neonatal Sepsis Patients During Admission to NICU of MizanTepi University Teaching Hospital, South West Ethiopia 202I ( $n=21$ I)

\begin{tabular}{|l|l|l|l|}
\hline Variables & Category & Frequency & Percentage \\
\hline Convulsion & Yes & 190 & 90 \\
& No & 21 & 10 \\
\hline Unconscious & Yes & 192 & 90.1 \\
& No & 19 & 8.9 \\
\hline RR>60 breath/min & Yes & 116 & 55 \\
& No & 95 & 45 \\
\hline Temperature & Yes & 155 & 73.5 \\
\hline Respiratory distress & No & 56 & 26.5 \\
\hline Yes & No & 133 & 63 \\
\hline Rethargic & Yes & 189 & 37 \\
\hline Reduced movement & Yes & 191 & 89.5 \\
& No & 20 & 10.5 \\
\hline Hodypotension & Yes & 46 & 9.5 \\
\hline Unable to breastfeed & No & 165 & 78.2 \\
\hline & Yes & 109 & 51.7 \\
& No & 102 & 48.3 \\
\hline & 60 & 151 & 71.6 \\
\hline & No & 28.4 \\
\hline
\end{tabular}

test for diagnosing of neonatal sepsis. Among those who had CBC, 23 (11.5\%) were reported high $(>20,000)$ WBC counts and eight $(4 \%)$ were low $(<5000)$ WBC counts. Among 25 patients for which culture was done, $14(56 \%)$ were culture positive results. Among 41 patients who had done gram stain, 23 (56.1\%) were positive (Table 5).

\section{Comorbidities}

Of the total neonatal sepsis patients, 72 (34.1\%) had comorbidities. Of these, 35 (48.6\%) were comorbid with severe acute malnutrition (SAM), 13 (18\%) were comorbid with congenital heart disease (CHD), $11(15.3 \%)$ were comorbid with acute gastroenteritis (AGE), nine (12.5\%) were comorbid with asphyxia, and four $(5.6 \%)$ were comorbid with other symptoms (Figure 2).

\section{Medication-Related Factors}

Of all neonatal sepsis patients, 165 (78.2\%) were treated by ampicillin + gentamycin, $18(8.5 \%)$ with a combination 
Table 5 Laboratory Findings for the Diagnosis of Neonatal Sepsis Patients Admitted to MTUTH, South West Ethiopia 202I ( $\mathrm{n}=2 \mathrm{II}$ )

\begin{tabular}{|c|c|c|c|}
\hline Variables & Category & Frequency & Percent \\
\hline \multirow[t]{3}{*}{ WBC counts/mm3(203) } & $5000-20,000$ (normal) & 172 & 84.7 \\
\hline & $>20,000$ (high) & 23 & 11.3 \\
\hline & $<5000$ (low) & 8 & 4.0 \\
\hline \multirow[t]{4}{*}{ Platelet counts $10003 / \mu \mathrm{L}(194)$} & $<50$ (extreme low) & 2 & I \\
\hline & $50-150$ (low) & 24 & 12.4 \\
\hline & 150-450(normal) & 147 & 75.7 \\
\hline & $>450$ (high) & 21 & 10.9 \\
\hline \multirow[t]{2}{*}{ Culture done (25) } & Culture positive result & 14 & 56 \\
\hline & Culture negative result & 11 & 44 \\
\hline \multirow[t]{4}{*}{ Types of the organism from culture } & GBS & 5 & 35.7 \\
\hline & E. coli & 4 & 28.5 \\
\hline & CONS & 3 & 21.4 \\
\hline & Listeria monocytogenes & 2 & 14.3 \\
\hline \multirow[t]{2}{*}{ Gram stain done $(4 I)$} & Positive & 23 & 56.1 \\
\hline & Negative & 18 & 43.9 \\
\hline \multirow[t]{4}{*}{ Types of the organism from gram stain } & Few gram +ve rods and many gram +ve cocci & 9 & 39.1 \\
\hline & Many diplococci & 6 & 26.1 \\
\hline & Streptococci & 5 & 21.7 \\
\hline & Many gram -ve rods and few gram +ve cocci & 3 & 13 \\
\hline
\end{tabular}

Abbreviations: WBC, white blood cell; GBS, group B streptococcus; CoNS, coagulase-negative staphylococcus.

of ampicillin, gentamycin, and ceftriaxone; 12 (5.7\%) with a combination of gentamycin and ceftriaxone followed by $10(4.7 \%)$ with a combination of ampicillin, gentamycin, and vancomycin (Figure 3).

Of all patients, $73(34.6 \%)$ were treated with an underdose of ampicillin that is $<100 \mathrm{mg} / \mathrm{kg} /$ day, and three $(1.4 \%)$ were treated with an overdose of ampicillin that is $>200 \mathrm{mg} / \mathrm{kg} / \mathrm{day}$. Among patients treated with gentamycin, $29(13.7 \%)$ were treated with an underdose $(<3.5 \mathrm{mg} / \mathrm{kg} /$ day $)$ and $55(26.1 \%)$ were treated with an overdose $(>7.5 \mathrm{mg} / \mathrm{kg} / \mathrm{day})$ (Figure 4).

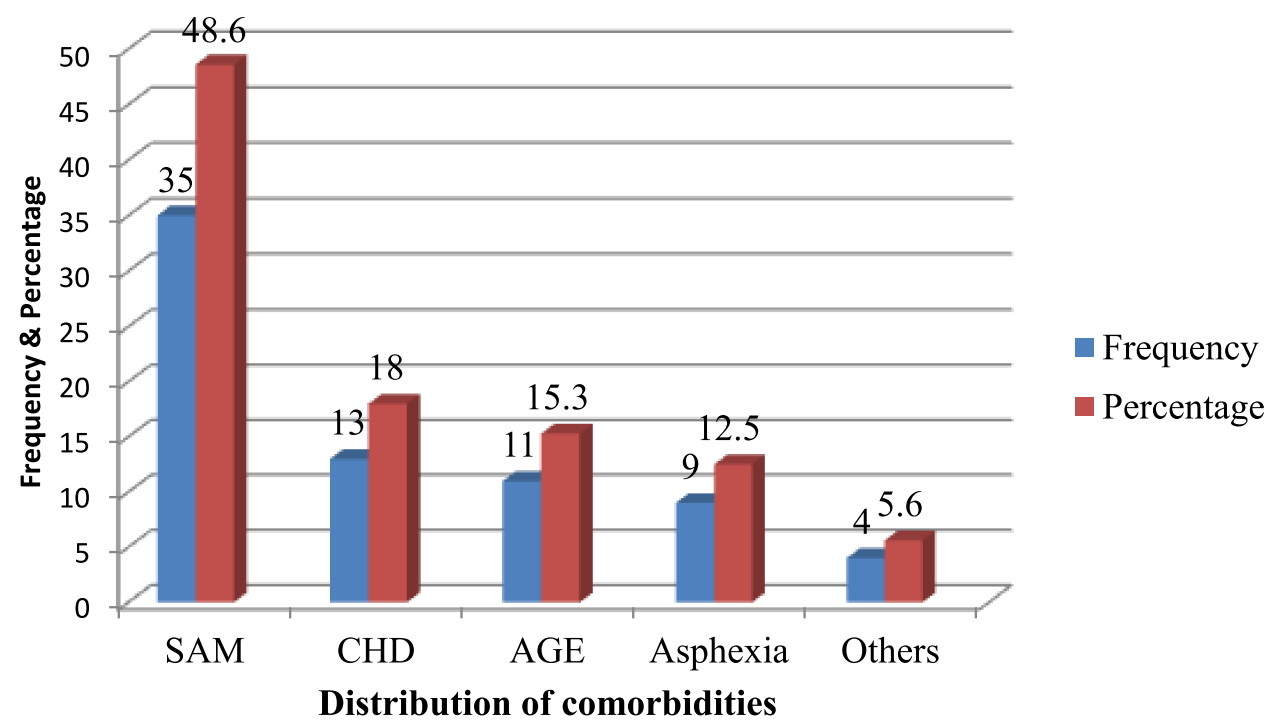

Figure 2 Frequency of comorbidities with neonatal sepsis patients admitted to Mizan Tepi University Teaching Hospital, South West Ethiopia between May I to November 30, $2019(n=211)$. 


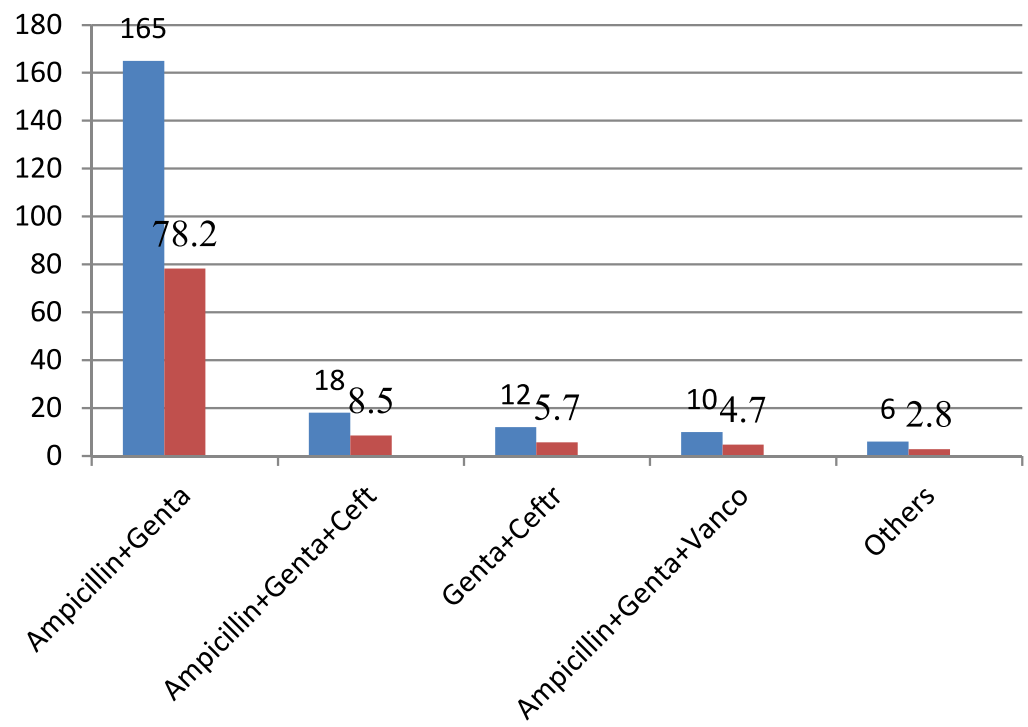

Frequency

Percentage

Figure 3 Percentage of medications regimens given for neonatal sepsis patients admitted to Mizan Tepi University Teaching Hospital, South West Ethiopia,202I $(n=2 \mathrm{I})$.

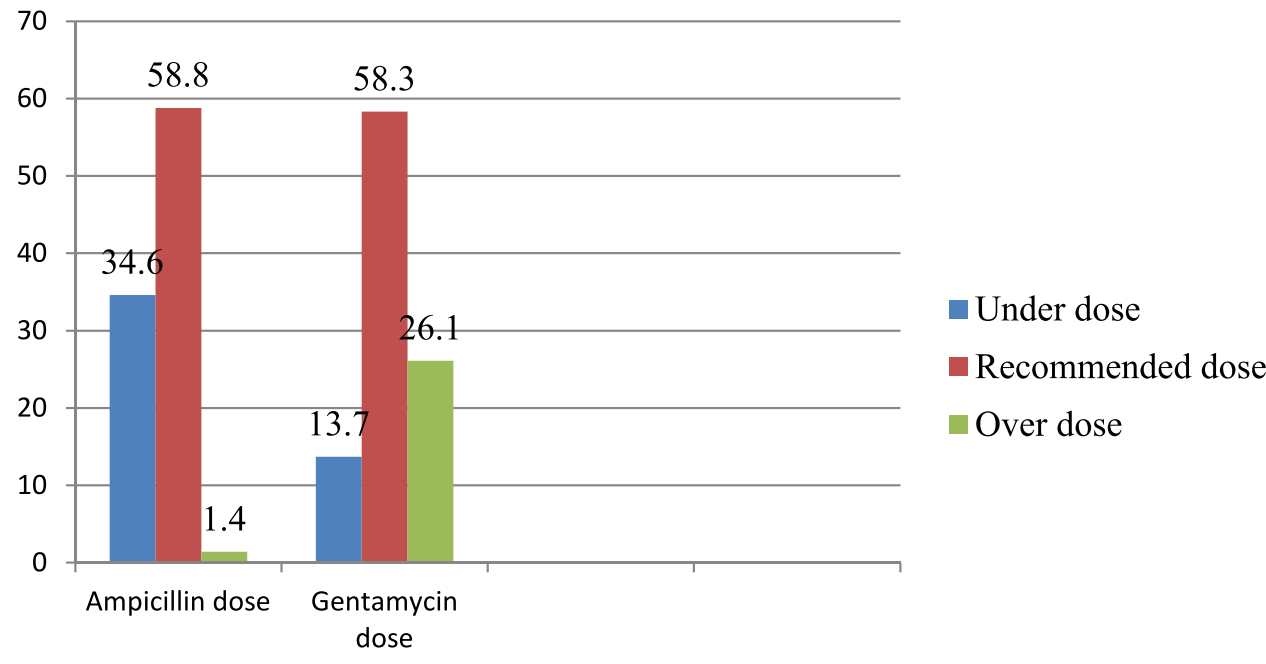

Ampicillin and Gentamycin dose range

Figure 4 Percentage of ampicillin and gentamycin dose range given for nNeonatal sepsis patients admitted to Mizan Tepi University Teaching Hospital, South West Ethiopia between May I to November 30, $2019(n=211)$.

\section{Treatment Outcome}

The treatment outcome of the study was a poor outcome and good outcome. Of all neonatal sepsis patients admitted at NICU, $143(67.8 \%)$ were discharged with good outcomes and 68 (32.2\%) were with a poor outcome. Among poor outcomes, 31 (14.7\%) died, $12(5.7 \%)$ developed complications, 12 (5.7\%) deteriorated, $3.3 \%$ self-discharged, and $2.8 \%$ were referred to other health institutions. Among complications, five $(41.6 \%)$ were meningitis, three (25\%) were septic shock, three $(25 \%)$ were respiratory failures and one $(8.4 \%)$ was symptomatic hypoglycemia (Figure 5).

\section{Bivariate and Multivariable Cox Regression Analysis Results for Factors Associated with Mortality}

In binary and multiple Cox regression analysis, maternal history of infection during pregnancy, very low birth weight, age of neonate less than 4 days, length of hospital stay, and maternal educational status, were significantly associated with mortality for neonatal sepsis patients. 


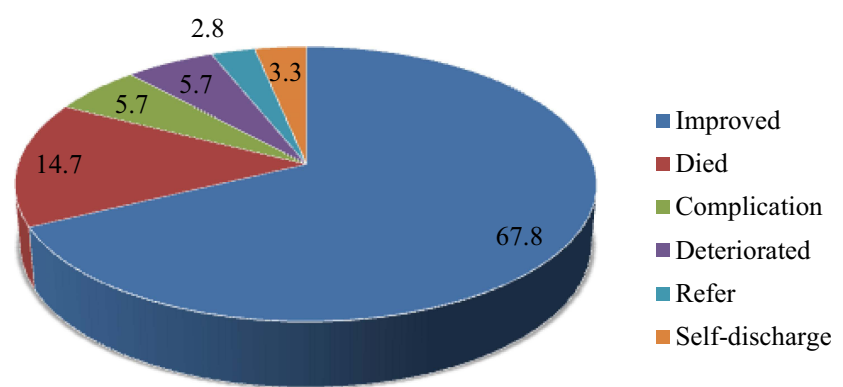

Figure 5 Percentage of treatment outcomes of neonatal sepsis patients admitted to Mizan Tepi University Teaching Hospital, South West Ethiopia between May I to November 30, $2019(\mathrm{n}=211)$.

Those neonates born from mothers who had a history of infection during pregnancy $[\mathrm{P}=0.032$, AHR $=3.186$, 95\% CI: $(1.32,30.68)]$ increased the risk of death by three times compared to those who were born from mothers who had no maternal infection during pregnancy. Those neonates with early-onset sepsis (EONS) $[\mathrm{P}=0.001, \mathrm{AHR}=$ 9.67, 95\% CI: $(2.24,41.70)]$ were 10 times more likely to suffer an early death or decreased survival compared to those neonates with late-onset sepsis (LONS). Neonates with very low birth weight (1000-1500 mg) [P=0.006, AHR $=1.692,95 \% \mathrm{CI}:(1.245,4.36)]$ were two times more likely to die compared to those who were born with a normal weight.

Neonatal sepsis patients who stayed for longer than 7 days in hospital $[(\mathrm{P}=0.017, \mathrm{AHR}=12.29,95 \% \mathrm{CI}:(1.55$, 96.31) were 12 times more likely to die compared to those who had a short hospital stay of $<7$ days. Those neonates born to mothers who attended up to secondary school $[\mathrm{P}=$ 0.008$, AHR $=0.180,95 \%$ CI: $(0.12,0.282)]$ were $82 \%$ less likely to die compared to those neonates born to mothers who had attended up to college and above. (Table 6).

\section{Survival Graph}

Survival analysis showed that the probability of survival of neonates with late-onset sepsis (LONS) was greater than neonates with early-onset sepsis $(\mathrm{P}=0.001)$. The probability of survival of late-onset sepsis patients during the first 3 days of admission was 1.0 while it was 0.7 in the early-onset neonatal sepsis (EONS), and the probability of survival of late-onset sepsis during the first 6 days of admission was 0.7 while it was 0.4 for earlyonset sepsis. The mean time taken for the early onset sepsis patients to die was $5.56 \pm 0.667$ days $(95 \% \mathrm{CI}$, 4.19-6.89) while it was $9.29 \pm 0.668$ days $(95 \% \mathrm{CI}$,
7.88-10.578) for late-onset neonatal sepsis patients. Early-onset neonatal sepsis $[\mathrm{P}=0.001, \mathrm{AHR}=7.24$, 95\% CI: $(2.16,24.29)]$ was 10 times more likely to cause death or decrease survival compared to late-onset neonatal sepsis. As time in hospital increased, the probability of survival decreased for both types of sepsis, but the probability of survival for LONS was greater than EONS (Figure 6).

\section{Discussion}

This study assessed the prevalence, outcome and associated factors among neonatal sepsis patients admitted to Mizan Tepi University Teaching Hospital, Southwest Ethiopia.

This study revealed that neonatal sepsis was a frequently occurring disease among neonates admitted to the NICU with a prevalence of $26.1 \%$. This was higher than the study done in the United States of America (USA). The prevalence of culture-proven neonatal sepsis is estimated to be 0.77 to 1 per 1000 live births, thus the prevalence and mortality are higher when very-low-birthweight (VLBW) infants, estimated to be 26 per $1000 .^{16}$ The possible explanation might be due to low socioeconomic status in this study setting.

This study was lower than a cross-sectional study conducted at Temeke and Mwananyamala Hospitals during August to September in Dares Salaam Tanzania, where prevalence was $31.4 \%{ }^{17}$ The possible explanation might be due to the difference in design and duration of the study and might be due to a poor caring system during delivery, high prevalence of maternal infection during pregnancy, overcrowding, or high patient to staff ratio in the previous study setting.

The finding of this study was lower than the study done in NICUs of two governmental hospitals in Shashemene town $(77.9 \%)$. From this $65 \%$ and $35 \%$ of neonates were early-onset neonatal sepsis and late-onset neonatal sepsis, respectively, $^{18}$ it was also lower than from another perspective cross-sectional study done in Bishoftu General Hospital, Neonatal Intensive Care Unit where the prevalence of neonatal sepsis was $72.22 \%{ }^{12}$ The difference might be due to the nature of the cross-sectional study design and the short duration of study in previous studies.

This study showed that among 211 neonatal sepsis patients admitted at the NICU of MTUTH, 67.8\% were good outcomes and $32.2 \%$ were a poor outcome, of which; $14.7 \%$ died, 5.5\% developed complications, 5.5\% deteriorated, $3.3 \%$ were self-discharged and $2.8 \%$ were referred. 
Table 6 Cox Regression Analysis for Factors Associated with Mortality Neonatal Sepsis Patients Admitted to Mizan Tepi University Teaching Hospital, South West Ethiopia, Between May I to November 30, 2019 ( $n=211)$

\begin{tabular}{|c|c|c|c|c|c|c|c|}
\hline \multirow[t]{2}{*}{ Variables } & \multirow[t]{2}{*}{ Category } & \multicolumn{2}{|c|}{ Treatment Outcome } & \multirow[t]{2}{*}{$\mathrm{CHR}(95 \% \mathrm{Cl})$} & \multirow[t]{2}{*}{ p-value } & \multirow[t]{2}{*}{ AHR(95\% C.I) } & \multirow[t]{2}{*}{ P-value } \\
\hline & & Survived & Death & & & & \\
\hline Marital status & $\begin{array}{l}\text { Married } \\
\text { Single } \\
\text { Widowed } \\
\text { Divorced }\end{array}$ & $\begin{array}{l}159 \\
6 \\
8 \\
7\end{array}$ & $\begin{array}{l}22 \\
7 \\
1 \\
1\end{array}$ & $\begin{array}{l}\text { I } \\
0.098(0.01,0.95)^{*} \\
0.116(0.01,0.122) \\
0.037(0.01,0.77)^{*}\end{array}$ & $\begin{array}{l}0.045 \\
0.073 \\
0.033\end{array}$ & $\begin{array}{l}1 \\
0.619(0.36,10.6) \\
0.244(0.10,6.128) \\
0.196(0.05,8.03)\end{array}$ & $\begin{array}{l}0.745 \\
0.391 \\
0.389\end{array}$ \\
\hline Mothers educations & $\begin{array}{l}\text { Illiterate } \\
\text { Read \& write } \\
\text { Primary } \\
\text { Secondary } \\
\text { College \&above }\end{array}$ & $\begin{array}{l}47 \\
67 \\
29 \\
28 \\
9\end{array}$ & $\begin{array}{l}12 \\
8 \\
2 \\
8 \\
1\end{array}$ & $\begin{array}{l}0.087(0.09,0.88)^{*} \\
0.097(0.09,1.01) \\
0.24(1.18,3.2) \\
0.087(0.08,0.92)^{*} \\
I\end{array}$ & $\begin{array}{l}0.039 \\
0.052 \\
0.28 \\
0.40\end{array}$ & $\begin{array}{l}0.012(0.01,0.4 I 3) \\
0.01 \mathrm{I}(0.001,0.324) \\
0.024(0.002, I .103) \\
0.180(0.12,0.282) \\
I\end{array}$ & $\begin{array}{l}0.014 \\
0.009 \\
0.056 \\
0.008^{*}\end{array}$ \\
\hline Maternal infection & $\begin{array}{l}\text { Yes } \\
\text { No }\end{array}$ & $\begin{array}{l}37 \\
143\end{array}$ & $\begin{array}{l}23 \\
8\end{array}$ & $\begin{array}{l}2.66(1.1,6.5)^{*} \\
I\end{array}$ & 0.030 & $\begin{array}{l}3.186(1.32,30.68) \\
1\end{array}$ & $0.032 *$ \\
\hline Mode of delivery & $\begin{array}{l}\text { Vaginal delivery } \\
\mathrm{C} / \mathrm{S}\end{array}$ & $\begin{array}{l}150 \\
30\end{array}$ & $\begin{array}{l}24 \\
7\end{array}$ & $\begin{array}{l}0.26(0.07 I, 0.95)^{*} \\
\text { I }\end{array}$ & 0.043 & $\begin{array}{l}0.325(0.05,20.56) \\
\text { I }\end{array}$ & 0.59 \\
\hline Birth weight & $\begin{array}{l}1000-1500 \\
|50|-2500 \\
250 \mid-4000\end{array}$ & $\begin{array}{l}14 \\
120 \\
34\end{array}$ & $\begin{array}{l}12 \\
10 \\
3\end{array}$ & $\begin{array}{l}0.25(0.65,0.95)^{*} \\
0.38(0.09,0.44) \\
\text { I }\end{array}$ & $\begin{array}{l}0.050 \\
0.165\end{array}$ & $\begin{array}{l}\mathrm{I} .692(\mathrm{I} .25,4.36)^{*} \\
0.253(0.043,1.48 \mathrm{I}) \\
\mathrm{I}\end{array}$ & $\begin{array}{l}0.006^{*} \\
0.127\end{array}$ \\
\hline Gestational age & $\begin{array}{l}<37 \\
37-42\end{array}$ & $\begin{array}{l}42 \\
138\end{array}$ & $\begin{array}{l}13 \\
18\end{array}$ & $\begin{array}{l}2.95(1.03,8.43)^{*} \\
1\end{array}$ & 0.043 & $\begin{array}{l}0.67 I(0.6 I, 7.39 I) \\
I\end{array}$ & 0.745 \\
\hline Types of sepsis & $\begin{array}{l}\text { EONS } \\
\text { LONS }\end{array}$ & $\begin{array}{l}36 \\
144\end{array}$ & $\begin{array}{l}14 \\
17\end{array}$ & $\begin{array}{l}3.16(1.45,6.88)^{*} \\
1\end{array}$ & 0.004 & $\begin{array}{l}9.67(2.24,41.70)^{*} \\
\text { I }\end{array}$ & $0.001 *$ \\
\hline Hospital stay & $\begin{array}{l}\text { I-7 days } \\
8-14 \text { days }\end{array}$ & $\begin{array}{l}129 \\
51\end{array}$ & $\begin{array}{l}10 \\
21\end{array}$ & I.13(1.52, 2.46)* & 0.076 & $\begin{array}{l}\text { I } \\
12.29(\mid .55,96.31)^{*}\end{array}$ & $0.017^{*}$ \\
\hline Comorbidity & $\begin{array}{l}\text { Yes } \\
\text { No }\end{array}$ & $\begin{array}{l}55 \\
125\end{array}$ & $\begin{array}{l}17 \\
14\end{array}$ & $2.25(1.633,7.98)^{*}$ & 0.210 & $\begin{array}{l}0.808(0.067,9.73) \\
\text { I }\end{array}$ & 0.864 \\
\hline
\end{tabular}

Notes: *p-value $<0.05$ (significant); I=reference.

This was lower than a retrospective case-control study conducted in Tamale Teaching Hospital, Northern Ghana indicated that the majority, $82.7 \%$ of the neonates, were successfully treated and discharged, $16.0 \%$ of them died. ${ }^{19}$ This might be due to a difference in study design.

This study agreed with a study done at a tertiary care center of Southern Punjab in Pakistan in 2014 which showed that, of the total neonatal admissions, $67 \%$ were discharged in a satisfactory condition, and $25.8 \%$ died, $3.9 \%$ were referred, $3.3 \%$ left against medical advice, ${ }^{33,35}$ it was also in line with a retrospective study done in a rural tertiary care center in Cameroon which showed an early neonatal mortality rate was estimated at $12.6 \%$ among neonatal sepsis patients on treatment. ${ }^{21}$ The outcome of this study was also consistent with a prospective cross-sectional study done in Bishoftu
General Hospital, Ethiopia which showed that the mortality rate was $13.1 \% .^{12}$

In the current study, the mortality rate was lower than an observational study conducted at Nashik Hospital in India which showed a mortality rate of $45.28 \%$ and a survival rate of $54.72 \% .^{22}$ It was also lower than a prospective cohort study which was done in Switzerland with blood culture-proven sepsis between September 2011 and December 2015 which showed that mortality was $30 \%$ of these, $18 \%$ for EOS and $12 \%$ for LOS. ${ }^{14}$ The possible explanation might be due to the larger sample size (444) used in the previous study (Switzerland) and maybe diagnosis or selection bias in the present study whereas culture-confirmed in Switzerland and due to dense population in a previous study (India). 


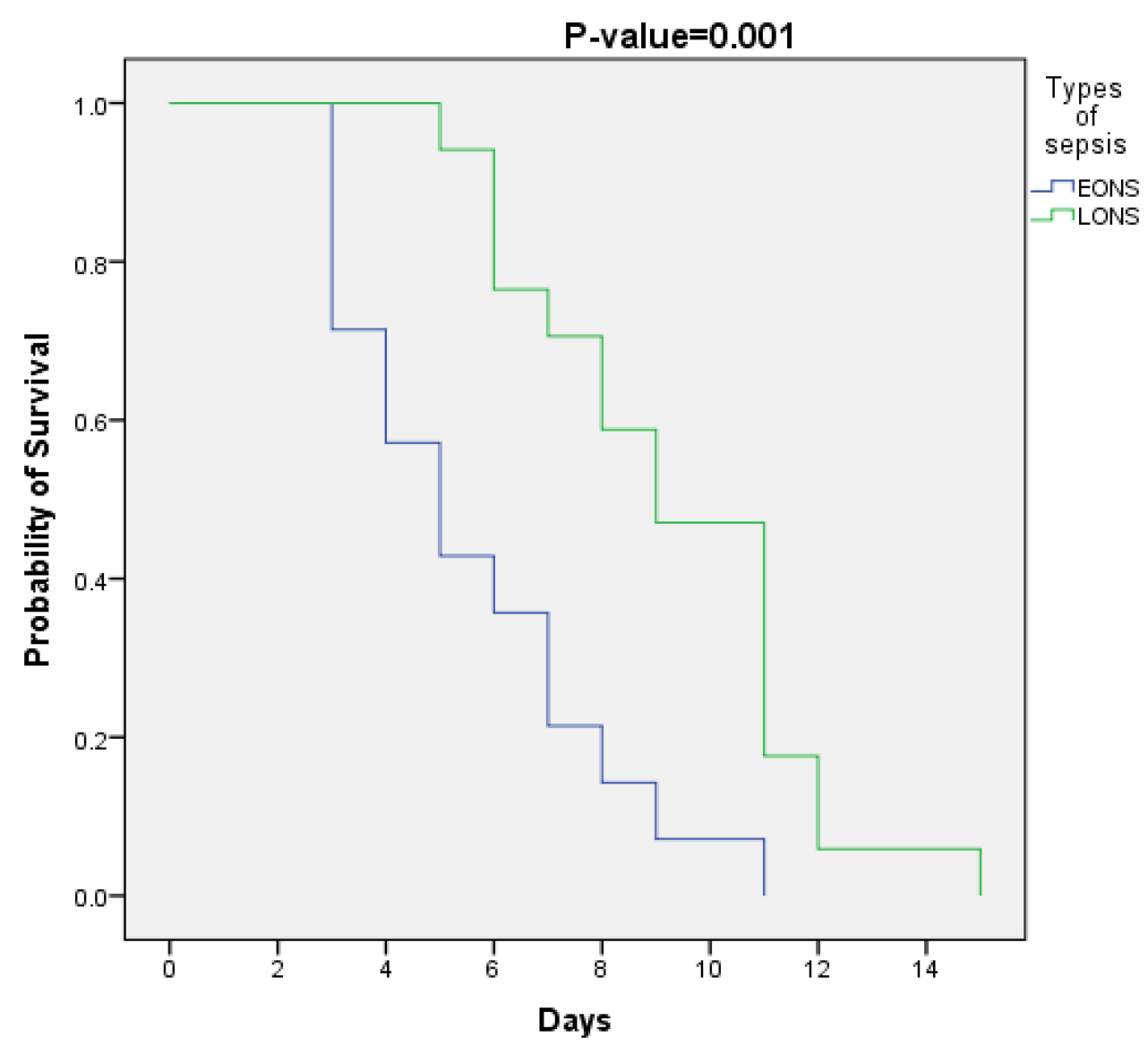

Figure 6 Kaplan-Meier estimation of survival among neonatal sepsis patients admitted to Mizan Tepi University Teaching Hospital, South West Ethiopia between May I to November 30, $2019(n=211)$.

The current finding was higher than a retrospective study done in the NICU of Manipal Teaching Hospital, Nepal where the mortality rate of neonatal sepsis was $10 \%$ and complication $7.5 \%,{ }^{23}$ also above a retrospective study carried out at the neonatal care unit of Raparin Pediatrics Teaching Hospital, Iraq showed that the neonate death rate was $5.4 \%$ and the majority $(87.9 \%)$ of neonates were discharged with an unspecified discharge outcome. ${ }^{20}$ The possible explanation might be due to the agent-specific antibiotic therapy in the above study, while empirical therapy is the routine practice in this study setup and also may be due to the prospective nature of the present study.

This findings were also higher than the retrospective chart review study conducted from 30 April to 30 May done at Bahir Dar Felege Hiwot Referral Hospital in Ethiopia, the clinical outcome of neonatal sepsis was not satisfied that, $84 \%$ improved after treatment, $4 \%$ died and $5.8 \%$ were referred to other organizations for further treatment. ${ }^{24}$ The possible explanation might be due to the retrospective nature study design and short period (1 month) duration in the previous study at Bahir Dar, Ethiopia.

In this study a maternal history of infection like UTI, very low birth weight, age of neonate less than 4 days, maternal education, and length of hospital stay were observed to be significantly associated with an increased risk of death for neonatal sepsis patients admitted at the NICU of MTUTH.

In this study, the age of neonates less than 4 days was detected as a significant predictor of mortality $[\mathrm{P}=0.001$, AHR $=7.24,95 \%$ CI: $(2.16,24.29)]$. This is supported by the studies done at a rural hospital in KwaZulu-Natal, South Africa. ${ }^{25}$ The possible explanation might be due to environmental sources or horizontal transmission of many types of microorganisms from direct contact of mothers because the fact that most early-onset sepsis is caused by pathogens (resistant strain) acquired from the mothers.

This study showed that a very low birth weight was detected as a significant predictor of mortality $[\mathrm{P}=0.006$, 
$\mathrm{AHR}=1.692,95 \%$ CI: $(1.245,4.36)]$. This finding is supported by a study conducted at a tertiary care hospital in the US low birth weight and preterm were significantly associated with neonatal morbidity ${ }^{26}$ another similar retrospective study conducted at a neonatal intensive care unit in Brazil, death in very low birth weight infants was statistically associated with a birth weight below 1000 g. ${ }^{27}$ Also in line with another study conducted in a tertiary care teaching hospital, Mandya India on the comparison of survival among different birth weights indicated that there was a statistically significant association with that more likely to cause death. ${ }^{28}$ The possible explanation might be due to structural and functional immaturity of organs, and due to being weak and poor breastfeeding as well as the relatively poor immune system in very low birth weight neonates that results in a death in both populations.

This study showed that a maternal history of infection during pregnancy was detected as a significant predictor of mortality $[\mathrm{P}=0.032$, AHR $=3.186,95 \%$ CI: $(1.32$, 30.68)]. This was supported with a study done at Bishoftu General Hospital, neonatal intensive care unit, in Ethiopia which shows that a significant number of neonates born from mothers' with urinary tract infections (UTI) developed sepsis and it was associated with mortality and this figure was almost 3 times higher compared to neonates born from mothers' with no UTI diagnosis. ${ }^{12}$ The possible explanation might be due to the chance of ascending an especially resistant strain of microorganisms from the birth canal into the uterus that leads to the patient poorly responding to treatment, ${ }^{29}$ and a prospective cohort study done in seven hospitals, in the Tigray region, Ethiopia, ${ }^{30}$ showed that a gestational age less than 37 weeks were factors independently associated with neonatal mortality, this is maybe due to incomplete functional and anatomical development for the previous study.

This study revealed that $37(17.5 \%)$ neonates were delivered through cesarean section, but this was not significantly associated with increased mortality, this might be due to a small number of neonates being delivered through the cesarean section in the current study, but a study conducted in the USA Washington Hospital Centre in Washington, DC's NICU indicates that newborns delivered by cesarean section were associated with an increased risk of mortality, ${ }^{31}$ this might be due to unclean surgical instrument used in the previous study.

\section{Strength and Limitation of the Study Limitation}

In this study, furthermost of the sepsis cases were not identified based on culture-confirmed sepsis. However, it was based on evocative clinical manifestation. This might expose the finding for selection bias because neonates who had signs and symptoms of sepsis could be negative for culture which is the golden standard for diagnosis of sepsis.

\section{Conclusion}

This study indicated that neonatal sepsis was a frequently occurring neonatal disease. Mortality was found to be very high among neonatal sepsis patients admitted to the NICU, which showed the need for quality care improvements. Maternal history of infection during pregnancy, age of neonate $<4$ days, birth weight of the neonate $<1500$ gm, maternal education, and prolonged length of hospital stay were found to be independent predictors of increased risk of mortality.

\section{Abbreviations}

ANC, antenatal care; ENS, early neonatal sepsis; EDHS, Ethiopian Demographic and Health Survey; EPI, expanded program on immunization; DHS, Demographic and Health Survey; HBV, hepatitis B virus; HIB, hemophilic influenza type b; LNS, late neonatal sepsis; $\mathrm{MOH}$, Ministry of Health; NS, neonatal sepsis; PROM, premature rupture of membrane; WHO, World Health Organization; SNNPR, South Nation, Nationality and People Region; COVID 19, coronavirus disease 2019.

\section{Data Sharing Statement}

Data is available from the corresponding author on reasonable request.

\section{Ethics Approval and Consent to Participate}

Ethical approval of the letter was gained From the Ethical Review Board of Jimma University and submitted to Mizan Tepi University Teaching Hospital to obtain authorization to collect the data. The participants were informed about the purpose of the study before the start of data collection. Verbal consent was taken from mothers or caregivers The participants' privacy was confidential and anonymous and in line with the Declaration of Helsinki. 


\section{Publication Consent}

Not relevant for this study.

\section{Acknowledgments}

Firstly we acknowledge the sperm God for everything in our life. Next, we acknowledge Jimma University research committee for their approval and encouragement doing so. Finally, we thank Mizan Tepi University Teaching Hospital administrators for their kindness and the volunteers to conduct this study.

\section{Author Contributions}

All authors had substantial input to this work, they were involved in the conception, designing, analysis, and interpretation of the data. All authors revised and criticized throughout the document. Finally, we all approve this article to be published in scientific journals and agreed to be responsible for all aspects of the work.

\section{Funding}

There was no funding for this study.

\section{Disclosure}

The authors report no conflicts of interest for this work.

This original article was submitted to the journal of Pediatric Health, Medicine and Therapeutics in Dove press based on an online thesis deposited in Jimma University but currently, the depository is not functional. All the data were used in this manuscript and the thesis itself is cited in this manuscript.

\section{References}

1. World Health Organization. Global health observatory data repository. 2012.

2. Schelonka RL, MacDonald MG, Seshia MMK, Mullett MD. Bacterial and fungal infections. In: Avery's Neonatology. 6th ed. Philadelphia: Lippincott Williams \& Wilkins; 2005.

3. Kayom VO, Mugalu J, Kakuru A, Kiguli S, Karamagi C. Burden and factors associated with clinical neonatal sepsis in urban Uganda: a community cohort study. BMC. 2018;18:1-8.

4. Jehan I, Harris H, Salat S, et al. Neonatal mortality, risk factors, and causes: a prospective population-based cohort study in urban Pakistan. Bull World Heal Organ. 2009;87:130-138. doi:10.2471/BLT.08.05 0963

5. Koda-Kimble MA, Young LY, Alldredge BK, et al. Applied Therapeutics: The Clinical Use Drugs. 9th ed. Lippincott Williams \& Wilkins; 2009.

6. Kraus DM, Pham JT. Neonatal therapy. In: KodaKimble MA, Yee YL, Alldredge BK, Guglielmo BJ, editors. Applied Therapeutics: The Clinical Use of Drugs. 9th ed. 2009.

7. Yohannes W, Legese CH. Treatment outcome and associated factors of neonatal sepsis at Mizan Tepi University teaching hospital, South West Ethiopia: a prospective observational study. 2020.
8. Coetzee M, Mbowane NT, De Witt TW. Neonatal sepsis: highlighting the principles of diagnosis and management. S Afr J Child Heal. 2017;11:99-103.

9. Melkie DA, Teferra E, Assefa M, et al. Food, medicine and healthcare administration and control authority of Ethiopia standard treatment guidelines for general hospital diseases investigations good prescribing \& dispensing practices for better health outcomes. 2014.

10. Kaistha N, Mehta M, Singla N, Garg R, Chander J. Neonatal septicemia isolates and 30 resistance patterns in a tertiary care hospital in North India. $J$ Infect Dev Ctries. 2009;4:5-7. doi: $10.3855 /$ jidc. 625

11. Marchant EA, Boyce GK, Sadarangani M, Lavoie PM. Neonatal sepsis due to coagulase-negative staphylococci. Clin Dev Immunol. 2013;2013. doi:10.1155/2013/586076

12. Woldu MA, Guta MB, Lenjisa JL, et al. Assessment of the incidence of neonatal sepsis, its risk factors, antimicrobials use, and clinical outcomes in Bishoftu General Hospital, neonatal intensive care unit, Debrezeit-Ethiopia. Int J Contemp Pediatr. 2014;1:135-141.

13. Saleem MU, Iqbal RA, Bokhari Set al. The pattern of neonatal admissions \& its outcome in a tertiary care hospital of Southern Punjab. PJMH S. 2014;8:916-921.

14. Giannoni E, Agyeman PK, Stocker M, et al. Neonatal sepsis of early onset, and hospital-acquired and community-acquired late onset: a prospective population-based cohort study. J Pediatr. 2018; 201:106-114.e4. doi:10.1016/j.jpeds.2018.05.048

15. Wynn JL. Defining neonatal sepsis. Curr Opin Pediatr. 2016;28:135-140. doi:10.1097/MOP.0000000000000315

16. Weston EJ, Pondo T, Lewis MM, et al. The burden of invasive early-onset neonatal sepsis in the United States, 2005-2008. Pediatr Infect Dis J. 2011;30:937-941. doi:10.1097/INF.0b013e31 8223bad2

17. Jabiri A, Wella HL, Semiono A, Sariah A, Protas J. Prevalence and factors associated with neonatal sepsis among neonates in Temeke and Mwananyamala Hospitals in Dar es Salaam, Tanzania. Tanzan $J$ Health Res. 2016;18:1-7. doi:10.4314/thrb.v18i4.4

18. Getabelew A, Aman M, Fantaye E, Yeheyis T. Prevalence of neonatal sepsis and associated factors among neonates in neonatal intensive care unit at selected governmental hospitals in Shashemene Town, Oromia Regional State, Ethiopia, 2017. Int J Pediatr. 2018;2018. doi:10.1155/2018/7801272

19. Walana W, Acquah Ekuban K, Abdul-Mumin A, Naafu B. Pattern, causes, and treatment outcomes of neonatal admission in the Tamale teaching hospital. Clin Mother-Child Heal. 2016;13:2.

20. Shaker NZ. Disease patterns and outcomes of neonatal admissions at Raparin Pediatric Teaching Hospital in Erbil City. Iraqi Nat J Nurs Specialties. 2015;28:39-46.

21. Koum D, Essomba N, Odile N, et al. Factors associated with early neonatal morbidity and mortality in an urban district hospital. Int J Latest Res Sci Technol. 2015;5:9-43.

22. Sonawane R, Patil S, Ahire NKN. The outcome of LBW babies admitted in the NICUA hospital-based study. MVP J Med Sci. 2014;1:71-74.

23. Shaw CK, Shaw P, Malla T, et al. The clinical spectrum and outcome of neonatal sepsis in a neonatal intensive care unit at a tertiary care hospital in western Nepal: January 2000 to December 2005 A retrospective study. East J Med. 2012;17:119-125.

24. Tewabe T, Mohammed S, Tilahun Y, Melaku B, Fenta M, Dagnaw T. Clinical outcome and risk factors of neonatal sepsis among neonates in Felege Hiwot referral hospital, Bahir Dar, Amhara Regional State, North West Ethiopia 2016: a retrospective chart review. BMC Res Notes. 2017;10:1-7. doi:10.1186/s13104-017-2573-1

25. Hoque M, Haaq S, Islam R. Causes of neonatal admissions and deaths at a rural hospital in KwaZulu-Natal, South Africa. South African J Epidemiol Infect. 2011;26:26-29. doi:10.1080/10158782. 2011.11441416 
26. Fox NS, Silverstein M, Bender S, et al. Active second-stage management in twin pregnancies undergoing planned vaginal delivery in a US population. Obstet Gynecol. 2010;115:229-233. doi:10.1097/ AOG.0b013e3181c8b462

27. Carneiro JA, Vieira MM, Reis TC, et al. Risk factors for the mortality of very low birth weight newborns at a neonatal intensive care unit. Rev Paul Pediatr. 2012;30:369-376. doi:10.1590/S0103-0582201200 0300010

28. Sridhar P, Thammanna P, Sandeep M. Morbidity pattern and hospital outcome of neonates admitted in a tertiary care teaching hospital, Mandya India. Int J Sci Stud. 2015;3:126-129.
29. Tekleab AM, Amaru GM, Tefera YA. Reasons for admission and neonatal outcome in the neonatal care unit of a tertiary care hospital in Addis Ababa: a prospective study. Res Reports Neonatol. 2016;6:17-23. doi:10.2147/RRN.S95455

30. Mengesha HG, Sahle BW. Cause of neonatal deaths in Northern Ethiopia: a prospective cohort study. BMC Public Health. 2017;17:1-8. doi:10.1186/s12889-016-3979-8

31. Chelliah AM, Vilchez G, Dai J, et al. Risk factors for neonatal intensive care unit admission after term twin deliveries. Obstet Gynecol. 2014;123:141S. doi:10.1097/01.AOG.0000447119.93694.1d

\section{Publish your work in this journal}

Pediatric Health, Medicine and Therapeutics is an international, peerreviewed, open access journal publishing original research, reports, editorials, reviews and commentaries. All aspects of health maintenance, preventative measures and disease treatment interventions are addressed within the journal. Practitioners from all disciplines are invited to submit their work as well as healthcare researchers and patient support groups. The manuscript management system is completely online and includes a very quick and fair peer-review system. Visit http://www.dovepress.com/testimonials.php to read real quotes from published authors. 